\title{
Evidence of gully formation by regional groundwater flow in the Gorgonum-Newton region (Mars)
}

\author{
Alvaro Márquez ${ }^{\mathrm{a}, *}$, Miguel Ángel de Pablo ${ }^{\mathrm{a}}$, Roberto Oyarzun ${ }^{\mathrm{b}}$, Cristóbal Viedma ${ }^{\mathrm{b}}$
}

\begin{abstract}
The discovery of gullies on Mars suggests liquid water activity near the surface of the planet in recent times. Since liquid water is unstable under the present-day P-T martian conditions, the formation mechanisms of the gullies, and the source of the putative water, have been a matter of debate for the last years. To provide new insights into these matters, we have approached the problem studying the gullies in relation to their regional setting. A major point in our study relates to the geographic orientation of gullies, an aspect that has been previously regarded as a crucial matter in different models, and has profound implications regarding their origin. We present a comprehensive and detailed survey of the Gorgonum-Newton region, and a study of the Dao and Nirgal Vallis regions. The survey was carried out with the aid of 965 high-resolution MOC images (752 for Gorgonum-Newton, 102 for Nirgal Vallis and 111 for Dao Vallis regions), and MOLA-derived DEMs. We found that gullies display a clear regional pattern, geographically and topographically consistent with a decreasing regional slope. We interpret the results in terms of the existence of several groundwater flow systems operating at different scales, which ultimately may have led to gully formation by seepage at the slopes of craters and canyons. We suggest that aquifers discharging at gully systems may have recharged from the surface, in response to the melting of young partially eroded ice-rich deposits.
\end{abstract}

Keywords: Mars; Geological processes

\section{Introduction}

The debate on the existence of water on Mars has lasted for years (see reviews in Carr, 1996 and Baker, 2001). The discovery of recent gullies on martian slopes (Malin and Edget, 2000) by means of the high-resolution images obtained by Mars Observer Camera (MOC) onboard the Mars Global Surveyor spacecraft (MGS), has highlighted this debate focussing it on the possible existence of near-surface liquid water on Mars in recent times. However, the origin of such gullies, and the source of liquid water under current $\mathrm{P}-\mathrm{T}$ conditions, has been a matter of debate for the last years (e.g., Malin and Edget, 2000; Mellon and Phil- lips, 2001; Musselwhite et al., 2001; Costard et al., 2002; Knauth and Burt, 2002; Christensen, 2003; Heldmann and Mellon, 2004; among others). The models proposed for gully formation involve processes with very different climatic implications: (1) groundwater seepage from a shallow water aquifer (e.g., Malin and Edget, 2000; Mellon and Phillips, 2001); (2) forced drain from a deep water aquifer (Gaidos, 2001); (3) melting of near-surface ground ice flowing from an aquiclude to the martian surface (Gilmore and Phillips, 2002); (4) local melting on near-surface ice deposits (e.g., Costard et al., 2002; Christensen, 2003); (5) action of liquid or gaseous $\mathrm{CO}_{2}$ (Hoffman, 2000; Musselwhite et al., 2001); or (6) dry mass avalanches (Treimann, 2003). In addition to the possible paleoclimatic implications derived from the discovery of gullies on Mars, an interpretation of the MGS images support the proposal that the planet would have 
undergone a recent ice age, which would have resulted in formation of an extensive ice mantle located at mid-latitudes (Head et al., 2003). The MOC high-resolution images provide evidence for recent climatic changes on Mars, involving the deposition and erosion of very young ice-rich deposits at mid-latitudes (between the $30^{\circ}$ and $60^{\circ}$ latitude bands; Mustard et al., 2001), precisely the region where gullies appear. Based on observed space-time relationship between gullies and recent eroded ice-rich deposits (both very young and at mid-latitudes) we suggest that the gully formation mechanism must be consistent with the recent martian climatic history.

According to previous authors, gullies would form preferentially on the poleward facing slopes of craters and canyons, specially at lower latitudes, because: (1) the colder conditions prevent the direct sublimation of water by the development of near-surface ground-ice plugs (Malin and Edget, 2000; Mellon and Phillips, 2001); (2) during highobliquity periods sufficient warming is produced to melt near-surface ice deposits (Costard et al., 2002); or (3) since snow accumulation is thick, the complete removal of the blanket is not rapid and therefore, melting at the base (and percolation of water) occurs before the snow is totally removed (Christensen, 2003).

However, Edgett et al. (2003) report gullies preferentially oriented on equator facing slopes in the northern hemisphere. Alternatively, Heldmann and Mellon (2004) propose that although gullies occur on all orientations of slopes (and therefore the poleward preference of gullies should not be overemphasized), their orientation vary by latitude. They report tendencies showing that gullies are preferentially found on poleward facing slopes at lower $\left(3^{\bullet}-44^{\bullet} S\right)$ and higher $\left(58^{\bullet}-72^{\bullet} \mathrm{S}\right)$ latitudes, but are preferentially on equatorward facing slopes in the middle $\left(44^{\bullet}-58^{\bullet} \mathrm{S}\right)$ latitudes. These trends of preferred orientation of gullies as a function of latitude are unresolved for their model of aquifer discharges in relation to climatic conditions (Mellon and Phillips, 2001; Heldmann and Mellon, 2004). Alternatively, these authors propose that the regional variations in the thermal properties of soil may compensate for the deviation from predications on gully orientations (Mellon and Phillips, 2001; Heldmann and Mellon, 2004).

Thus, in our opinion one key question emerging from previous models is: do gullies always occur in 'climatic-related' scenarios? The answer to this question is one of the main aims of this research, to check the validity of this argument, because if gullies occur in any position, independently of climatic factors (i.e., regardless of their latitude and solar orientation), then a different explanation for their origin must be offered. Alternatively, we suggest that if gullies are produced by groundwater seepage, this must be reflected in their spatial distribution, because this process implies, whatever the dimensions of the aquifer, a groundwater flow induced by a hydraulic gradient. The direction of such hypothetical groundwater flow must be indicated by the spatial position and orientation of gullies. To study the implications of this idea we plotted vectors on maps indicating the orientation of these erosional features at each of the localities where gullies occur. If gully formation was related to climatic processes, we should find a spatial correlation between latitude and vector orientation. On the contrary, if gullies are indeed related to groundwater seepage, then we should be able to observe a pattern consistent with the direction of the hypothetical groundwater flow. Thus, in this work we propose new observational constraints based on the combined geographic-topographic approach to the problem (MOC images and MOLA-derived DEMs) to test the source of water involved in gully formation. We also discuss the implications of our results within the context of the recent climatic evolution of Mars

\section{Methodology}

In order to constrain the origin of gullies and their hydrogeologic and paleoclimatic implications, we followed a different approach to other global-scale works (e.g., Heldmann and Mellon, 2004), studying these morphological features in relation to their regional setting. We checked the orientation (angle with respect to geographic pole) and location of gullies in each locality. We followed this approach because previous works have suggested that gully orientation is related to its origin (e.g., Malin and Edget, 2000; Costard et al., 2002; Christensen, 2003). We carried out a comprehensive survey of the Gorgonum-Newton region $\left(30^{\bullet}-55^{\bullet} \mathrm{S}, 180^{\bullet}-210^{\bullet} \mathrm{E}\right.$; anarea of $\sim 2 \times 10^{6} \mathrm{~km}^{2}$ ) (Fig 1), and chose the Dao Vallis $\left(85^{\bullet}-95^{\bullet} \mathrm{E} ; \mathbf{3 0}^{\bullet}-40^{\bullet} \mathrm{S}\right)$ and Nirgal Vallis $\left(-46^{\bullet},-36^{\bullet} \mathrm{E} ; 24^{\bullet}-30^{\bullet} \mathrm{S}\right)$ regions to test our ideas. We selected Gorgonum-Newton region because it hosts numerous outstanding clusters of gullies, which occur within a complex topographic setting involving several huge basins (Gorgonum, Newton, Copernicus), within a geologic realm that includes cratered and ridged plains, a probable ancient system of lakes (Irwin et al., 2002), and important tectonovolcanic activity (Wilson and Head, 2002). Our detailed survey of Gorgonum-Newton region was based on the study of 752 high-resolution MOC images (gullies were identified on $177 \mathrm{MOC}$ images) belonging to the series $\mathrm{ABl}$ to R15 (Fig. 1), obtained from September 1997 to March 2004, and a MOLA-derived DEM. At Nirgal Vallis $102 \mathrm{MOC}$ images were analyzed, and gullies are present on 12 images, whereas at Dao Vallis 111 MOC images were analyzed, with 22 of them containing gullies.

Gullies were morphologically identified based on the presence of channels emanating from an eroded alcove and leaving a debris apron. When gullies are cut off in the MoC image we just confirm the positive identification of a gully system by the presence of alcoves and channels. Besides, as stated above, instead of focussing on the morphology of individual features, we paid special attention to their orientation, spatial distribution, and topographic setting. Therefore, we have no made attempt to either measure any morphological 


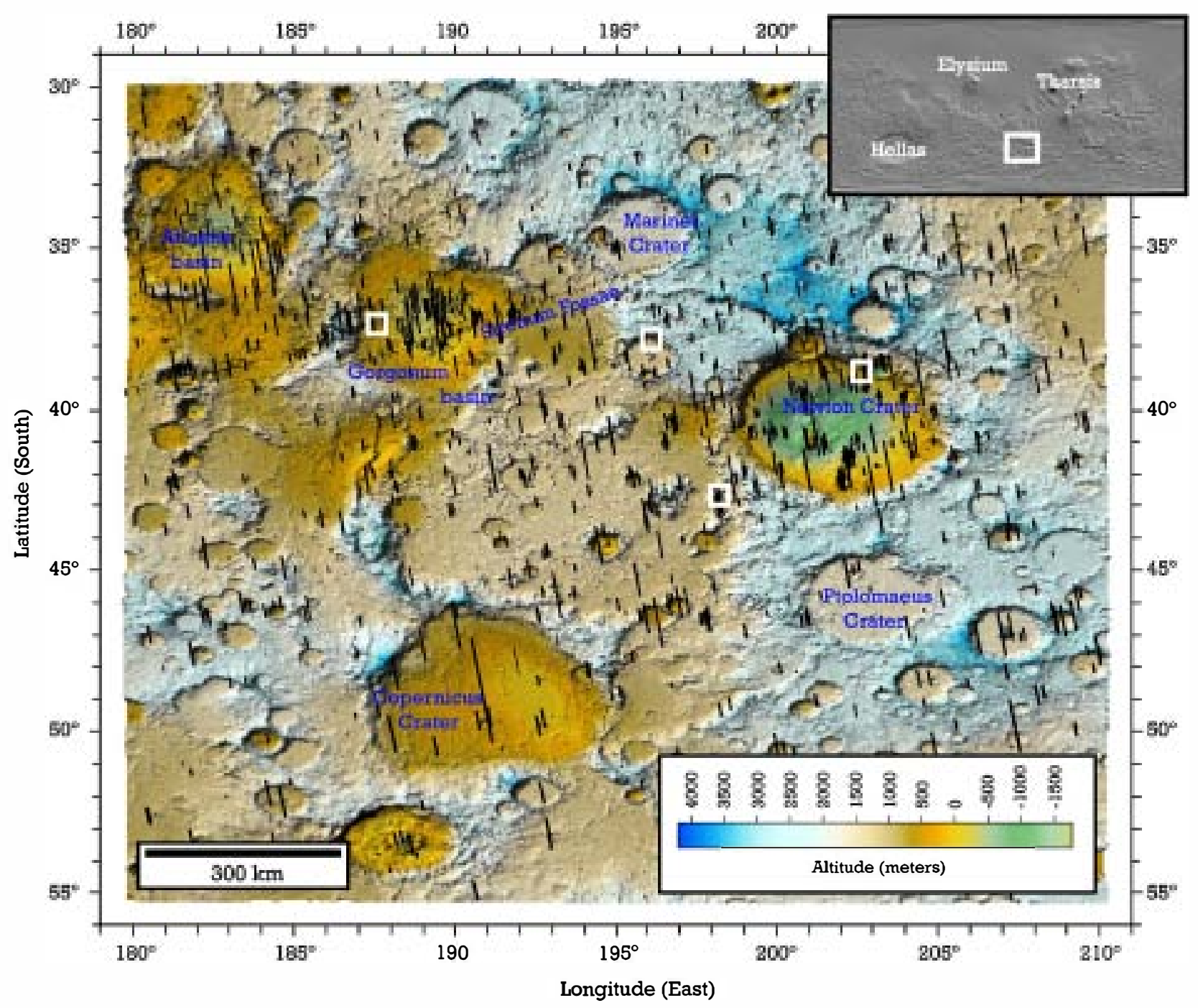

Fig. 1. MOLA-derived shaded relief image of the area covered by the regional study (see inlet for location at a larger scale). Black strips show the location of the 752 MOC images analyzed in this work. Open boxes show the location of MOC images shown in Fig. 8.

parameter of gully systems, or obtain the MOLA elevation of each gully system. Instead, we plotted on a topographic map the vectors showing the location and orientation of each gully system (Fig. 2).

\section{Regional distribution of gullies: Results}

We found 177 MOC images for the Gorgonum-Newton region, corresponding to 69 different localities where gullies occur on the slopes of craters, canyons and mesas (Fig. 2). Table 1 shows a complete list of MOC images showing gullies in the area. The results of the survey show a complex geographic pattern in which multiple orientations are recognized (Fig. 2). At a first glance, one may still argue that since the south(pole)ward direction is dominant at latitudes between $30^{\circ}$ and $40^{\circ} \mathrm{S}$, and variable orientations are found at higher latitudes (Fig. 2), climate controls the appearance of gullies. In principle these results would agree with the proposals of Heldmann and Mellon (2004) on the preferred orientations of gullies as a function of latitude. However, the combined approach to the problem, using MOC images and MOLA-derived DEMs allows the introduction of a second and key variable in the study: topography. When this factor is considered in the analysis, a much more clear picture emerges, with the gullies following a pattern defined by the regional slope. In other words, gullies appear on the side oriented down the regional slope (Fig. 2). The only exceptions to this pattern are three gully locations in the plains south of Sirenum Fossae and two in the NE rim of Copernicus Crater (see details below), together with those located on the slopes of isolated mesas into Gorgonum Chaos. The best examples of gully orientation as a function of regional slope are found in Newton Crater and its surroundings, where gully orientation is mainly radial to the center of the basin, and also radially distributed from the high elevation sites (Fig. 3). No latitudinal trends can be advocated to explain this distribution. For example, at latitude $40^{\circ} \mathrm{S}$ the gullies 


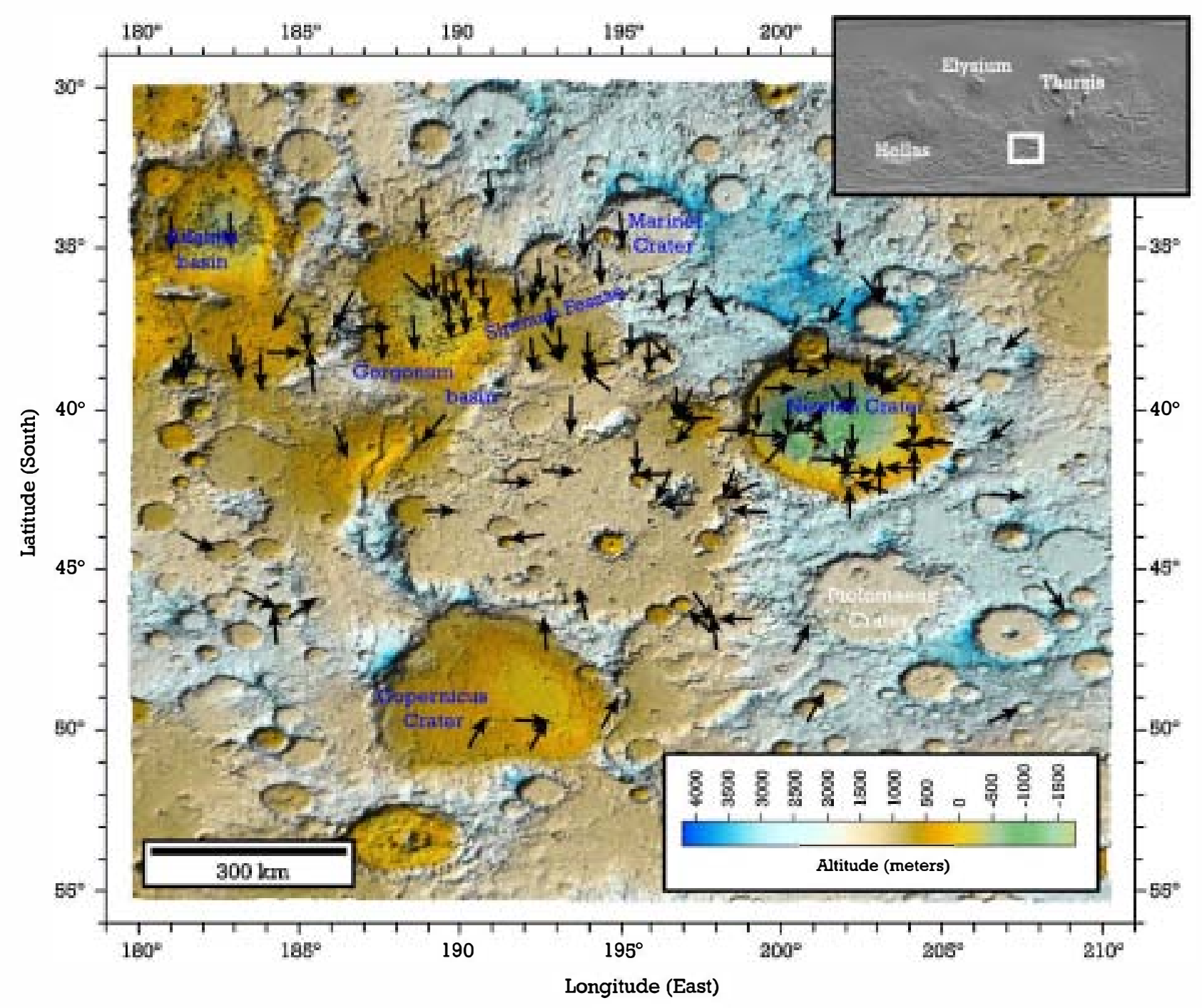

Fig. 2. Arrows indicate the orientation of gullies within the study area over a MOLA-derived shaded relief image. The arrows are oriented following a pattern defined by the regional slope, thus suggesting that gullies appear on the side oriented down the slope.

on the eastern side of Newton Crater are mainly oriented to the west, those located on the western side of the crater are mainly oriented to the east, and gullies located west of the western rim of the crater are oriented to the west and south. This radial distribution is not so obvious in other craters and basins of the area. In the Gorgonum sector or the Mariner Crater the general southward decrease in altitude leads to gully formation following the regional slope, thus giving the impression that gullies are poleward oriented (Fig. 2). This general southward trend is also observed on the plains located south of Sirenum Fossae between Gorgonum Basin and Mariner Crater. These southward oriented gully systems (Fig. 2) apparently contradict the relationship between the regional slope and gully orientation. However, a closer inspection of the topography (Fig. 4) reveals that most of the gully systems are also oriented down the regional slope, with two apparent exceptions in the gullies occurring in the southernmost canyon of the Sirenum Fossae system, and in the craters close to the centre of the plains $\left(38.5^{\circ} \mathrm{S}, 193.2^{\circ} \mathrm{W}\right)$. In Copernicus Crater the number of gully systems is much less than in other basins, and all the gullies are northward oriented. However, the topography of the area (Fig. 5) reveals that the two gully locations within the basin are clearly oriented following the regional slope (from the southern rim of the crater to the centre). There are also two apparent exceptions in the two northward oriented gullies located on the NE rim of Copernicus (Fig. 5). Whatever the case, the suggested general regional pattern of gullies, oriented downhill the regional slope, is consistent with groundwater flow systems running from high- to low-elevation domains, thus mimicking the topography of the surface. This is exactly the general dynamic behavior that we would expect in large scale groundwater systems. On the other hand, a trend of this kind is unresolved in the climatic-controlled scenarios, because it is hard to explain how climatic factors would produce, following the slopes and independently of latitudes and orientations, the colder or warmer conditions required by these models (Malin and Edget, 2000; Costard et al., 2002; Mellon and Phillips, 2001; Christensen, 2003). 
Table 1

List of MOC images showing gullies in Gorgonum-Newton region

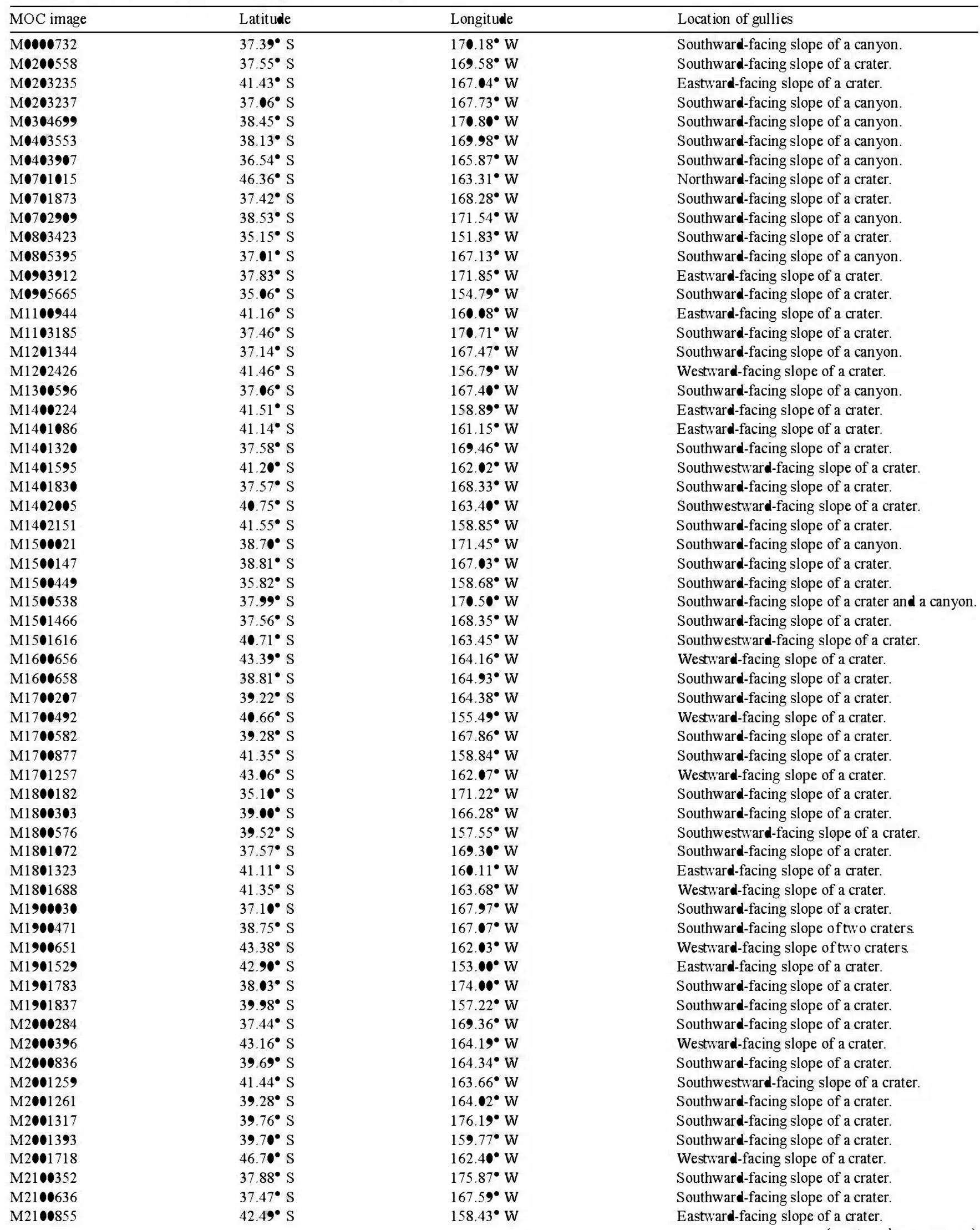




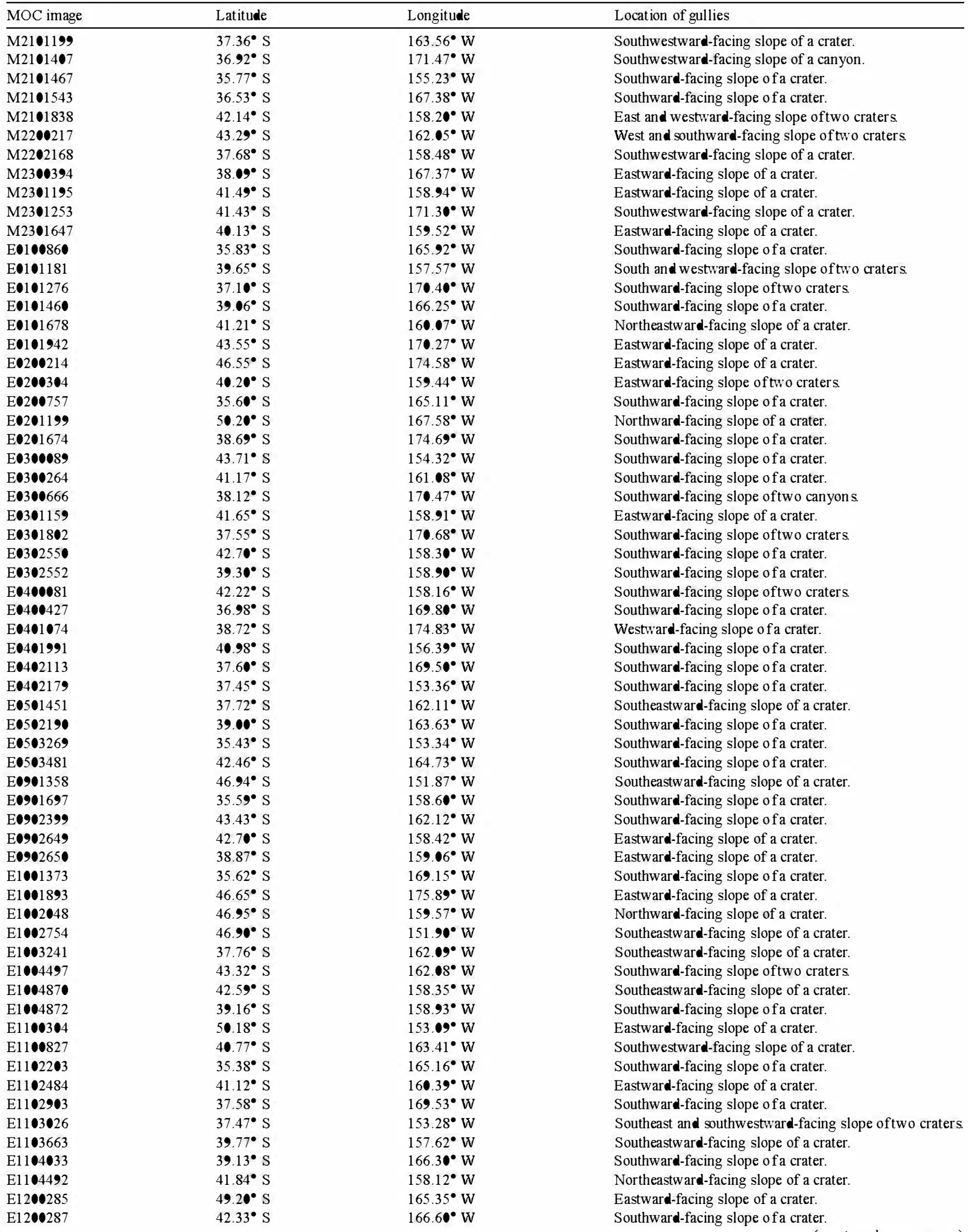




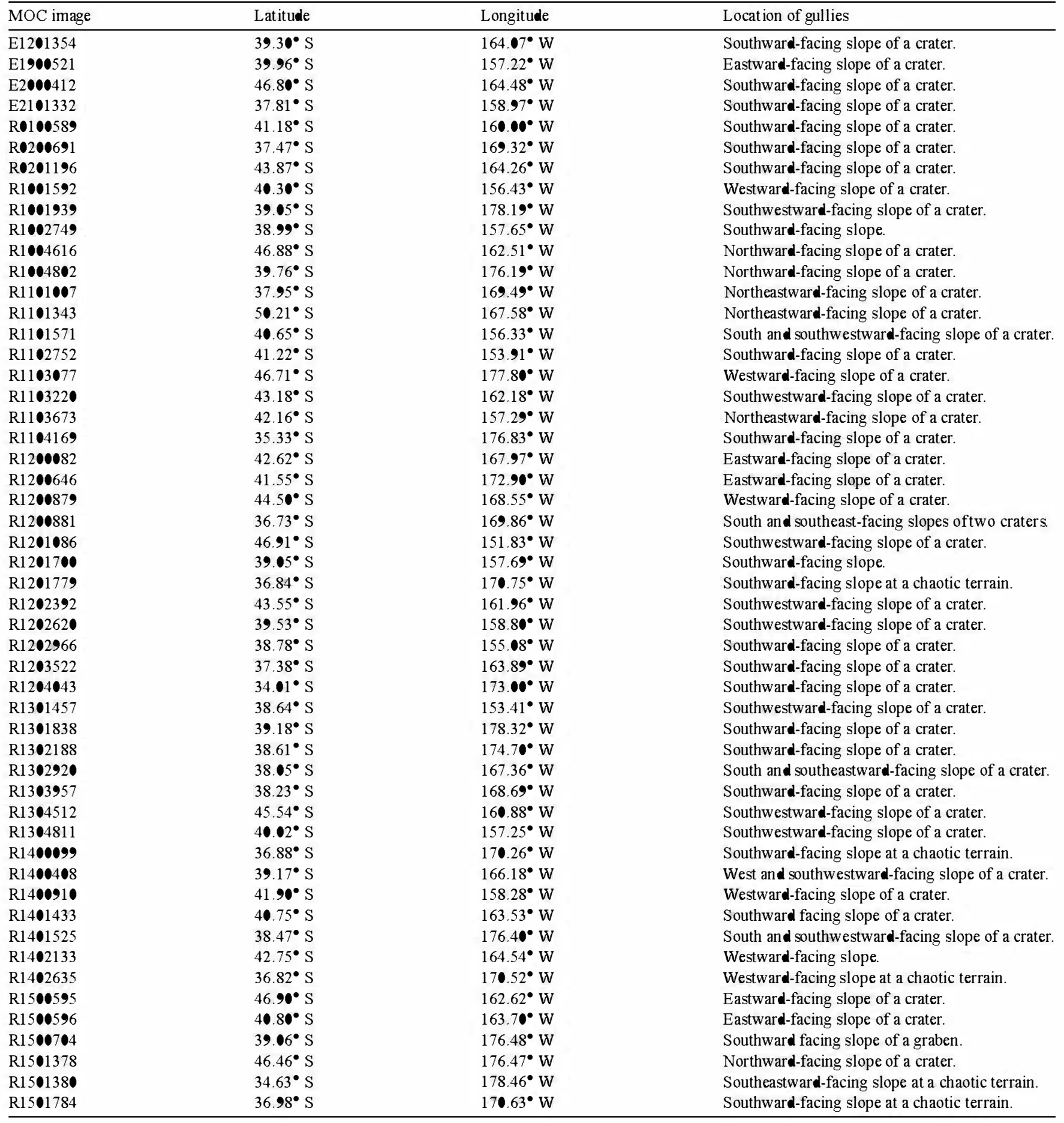

\section{Discussion}

\subsection{Groundwater flow systems in Gorgonum-Newton area}

Our regional analysis of the Gorgonum-Newton area shows that the spatial distribution and orientation of gullies is mainly controlled by the regional slope. This suggests that the emergent groundwater provides more than a plau- sible origin for the gullies, thus implying the existence of recent martian groundwater flow systems. If the distribution of the arrows plotted in Fig. 2 is truly indicative of groundwater flow directions, then several flow systems, with different characteristics have operated in the area. The arrows in Newton Crater would indicate a well-defined flow system from the high-altitude rims to the lowlands of the center of the basin. If this is correct, then groundwater flowed along 


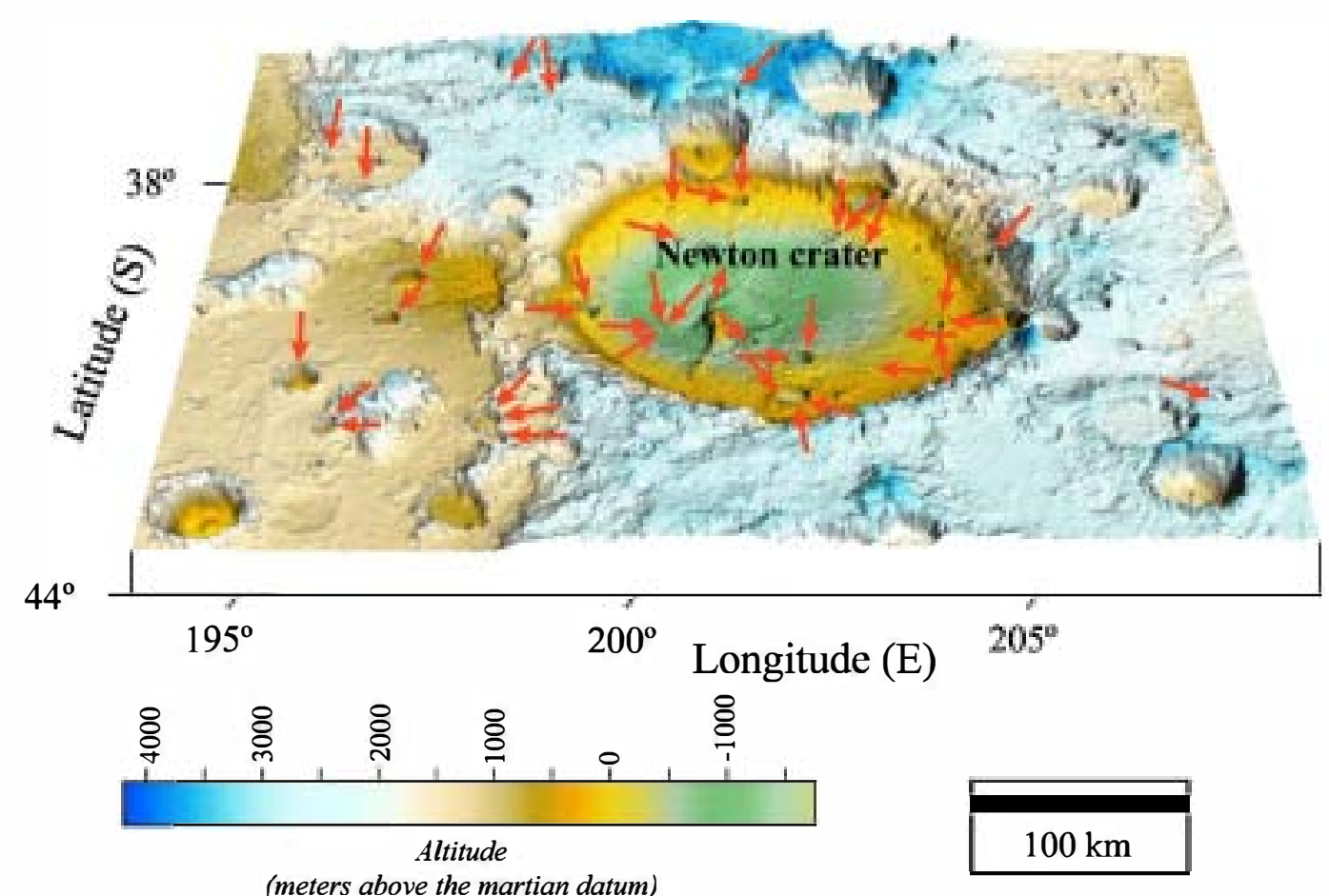

Fig. 3. Detailed view of the orientation of gullies in Newton Crater region. Note the outstanding changes in orientation of the arrows, showing no dominant geographic direction. However, it can be clearly seen that the gullies are radially oriented to the center of the basin, and from the high-elevation rim of SW Newton to the adjacent lowlands.

paths tens of kilometers long across an altitude gradient of more than $3000 \mathrm{~m}$ (from the $2500 \mathrm{~m}$ of altitude rims to the $-1000 \mathrm{~m}$ altitude center of the basin). Conversely, given that gullies are closer to the highlands in the plains west of Newton Crater, the flow systems would have smaller horizontal and vertical dimensions. Besides, some gully systems may have been produced by seepage from local groundwater systems, such as those labeled A in Fig. 4, located downhill of neighboring high-elevation areas. Gullies located on the slopes of isolated mesas into Gorgonum Chaos may represent local systems where water percolated from the surface of the mesa and seepage after a short flow. The few locations where gullies do not appear to follow the regional slope are more difficult to explain within this scheme of groundwater flow systems. These gully systems could be indicative of some additional contribution of climatic factors in gully formation. However, our results indicate that this contribution would be minimal compared to the role of groundwater flow following regional topography.

A local estimation of the amount of water that flowed in our suggested hydrologic system may be provided by studying the volume of debris deposits present in Newton Crater. Following Malin and Edget (2000) we have assumed that aprons of gully systems are formed by debris flow containing around $10 \%$ by volume water. We measured the surface covered by some of the aprons in Newton Basin, and obtained an area of around $3.75 \times 10^{6} \mathrm{~m}^{2}$. Assuming a mean thickness of $2 \mathrm{~m}$, we can estimate a volume of water in the order of $750,000 \mathrm{~m}^{3}\left(750 \times 10^{6} 1\right)$. Due to the scarcity of images showing complete debris aprons systems, we could only measure debris flow deposits at six different localities; therefore this relatively low amount of water must be taken as a minimum.

If gullies on Gorgonum-Newton region have been produced by seepage from the proposed groundwater flow systems, then we must assume that water moved within the rock formations of the area. The existence of several flow systems, at different scales, suggests that instead of a large water reservoir in the area, several isolated aquifers could better account for the distribution of gullies. Additionally, given that the discharge of groundwater is produced on the slopes of canyons and craters, at depths of a few hundred meters, these aquifers must occur at shallow depth (e.g., Heldmann and Mellon, 2004). The geological mapping (Scott and Tanaka, 1986) and analysis of the layers visible on the MOC images suggests that the aquifers could be mainly hosted by old volcanic rocks. Due to the rugged character of the surface of lava flows, volcanic rock successions usually have the highest permeability parallel to the bedding. Therefore, a simple model based on terrestrial volcanic aquifers would irvolve groundwater moving within and along bed-rock layers until it discharges at the surface on the slopes of craters and canyons. Although aquicludes play an important role in the location of springs in terrestrial volcanic aquifers, our model for Mars neither excludes not confirms their role in the generation of gullies (e.g., Gilmore and Phillips, 2002). A comparison with volcanic terrestrial aquifers also gives support to the dimensions of the flow systems deduced from Fig. 2. For example, the groundwater flow systems in the aquifers of Columbia River Basalts 


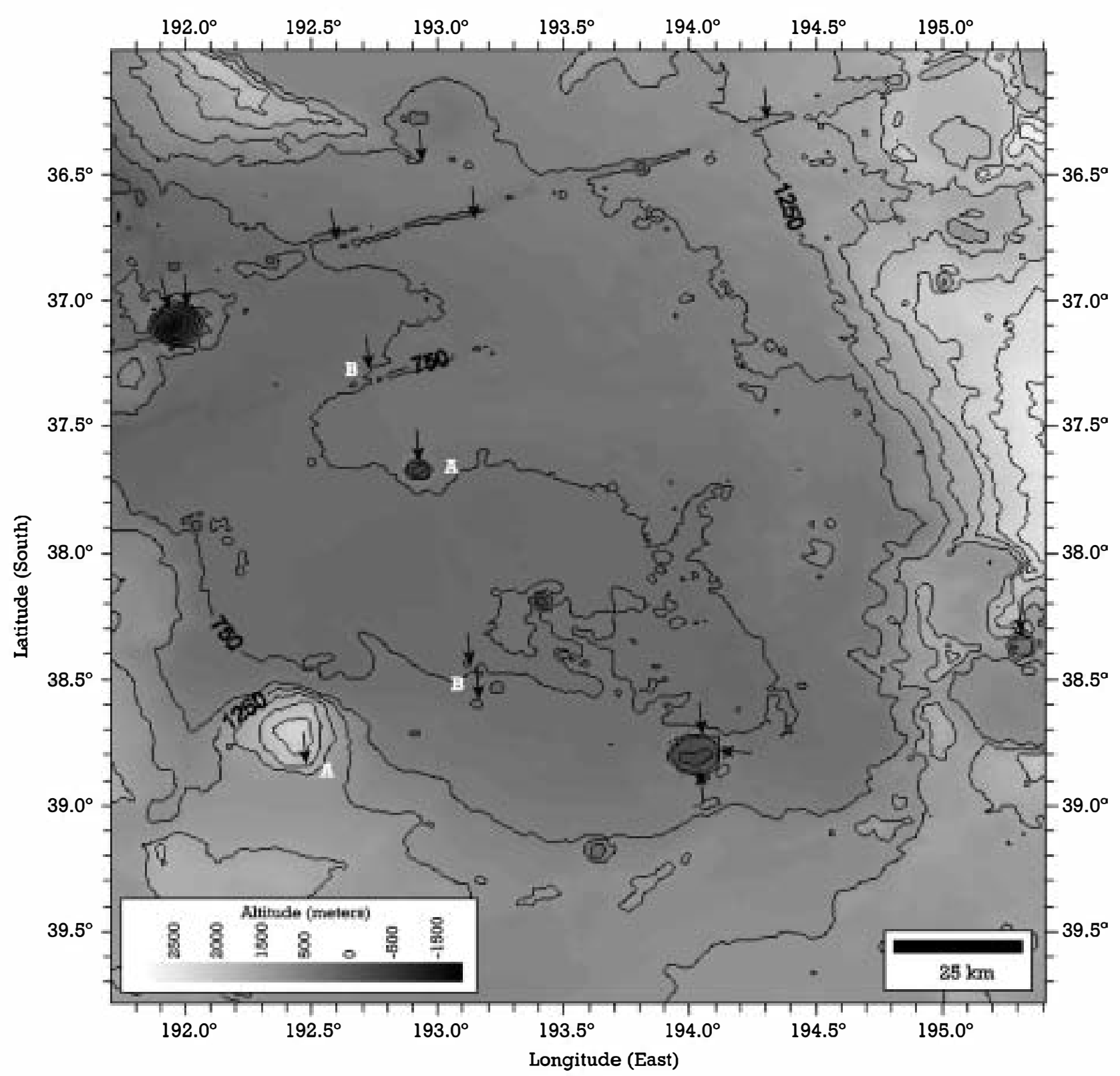

Fig. 4. MOLA-derived topographic map of the plains located SE of Gorgonum Basin, showing the orientation of gullies in the area. Note that most of the gully systems are oriented downhill the regional slope, and some may have been produced by seepage down of neighboring high elevation areas from local groundwater systems (A). There are only two apparent exceptions (B) in the southernmost canyon of the Sirenum Fossae system, and in two craters close to the centre of the plains.

and Snake River Plain (USA) can be up to hundreds of kilometers long.

Groundwater flow systems in volcanic islands such as Hawaii or Tenerife (Canary Islands) may have dimensions from several kilometers long to localized perched aquifers. Groundwater seepage from terrestrial volcanic aquifers can generate landforms morphologically analogous to martian gullies. For example, striking equivalent landforms (Fig. 6) are observed in the warm and wet environments from La Gomera (Canary Islands), which are produced by groundwater seepage at the contact between permeable upper pahoehoe lavas and older altered volcanic rocks. Therefore, in addition to previous proposals based on terrestrial landforms, suggesting that gullies could be formed by the melting of surface snow patches in cold environments (Lee et al., 2002; Hartmann et al., 2003), there are also equivalent morphological features in subtropical environments to those found in Mars. Thus, any model on gully formation based only on morphological criteria of terrestrial analogs should be taken with caution.

\subsection{Clues from other clusters of gullies: Nirgal and Dao Vallis areas}

In order to test our ideas on the relationships between gully orientation and regional relief, we applied our ap- 


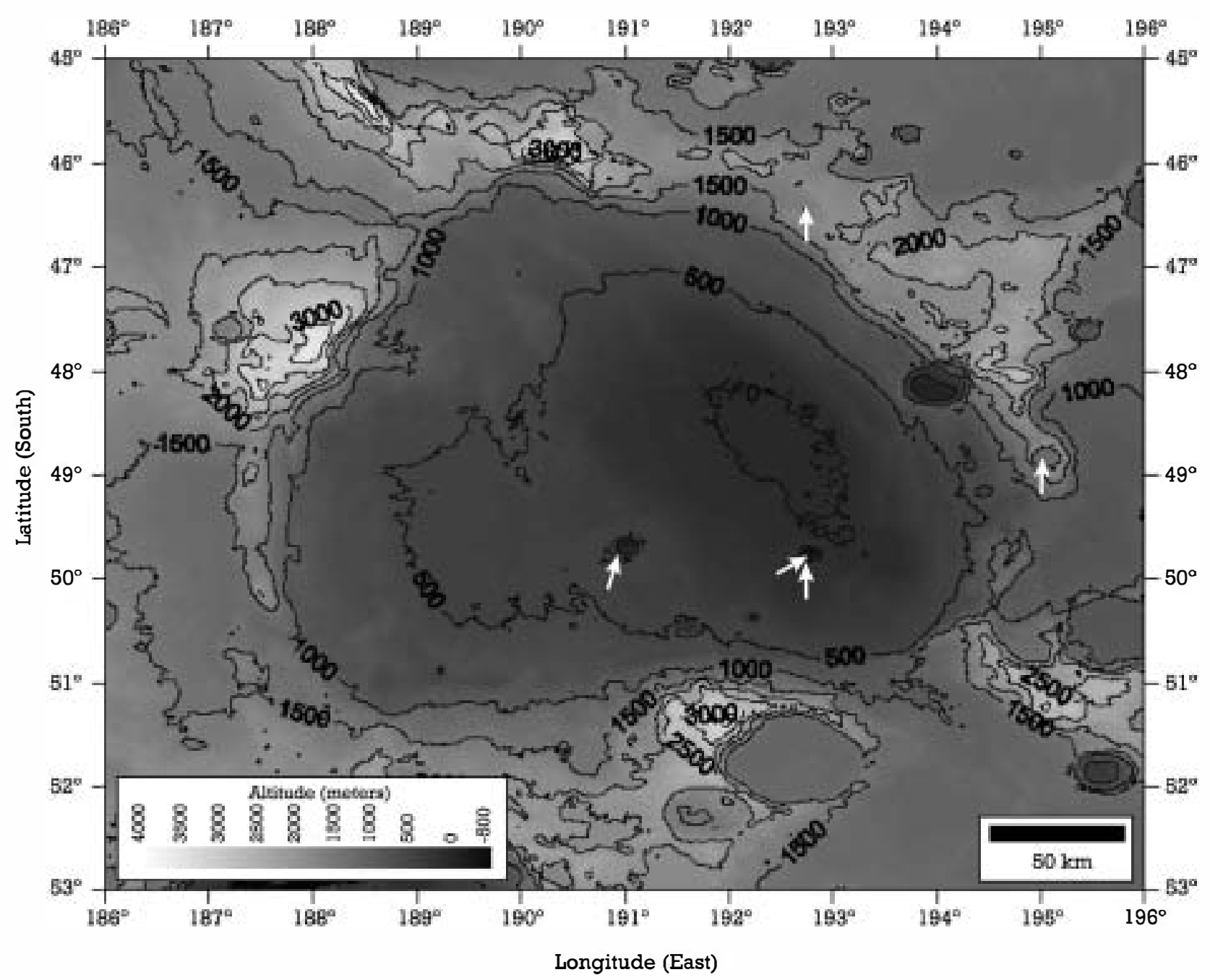

Fig. 5. Topographic map of Copernicus Crater showing the orientation of gullies in the area. The two locations inside the basin are clearly oriented following the regional slope, whereas the sites on the NE rim constitute two apparent exceptions to the downhill-oriented trend of gully systems.

proach to other regions of Mars where important clusters of gullies occur. We selected Nirgal Vallis $\left(-46^{\circ},-36^{\circ} \mathrm{E}\right.$; $24^{\circ}-30^{\circ} \mathrm{S} ; 102 \mathrm{MOC}$ images analyzed, 12 containing gullies) and Dao Vallis $\left(85^{\circ}-95^{\circ} \mathrm{E} ; 30^{\circ}-40^{\circ} \mathrm{S} ; 111 \mathrm{MOC}\right.$ images analyzed, 22 containing gullies), because a preliminary regional study on gully systems related them to water percolating and flowing from aquicludes (Gilmore and Phillips, 2002). Our maps show (Fig. 7) a pattern for gullies basically defined by the regional slope. Gullies appear mainly on the northern side of the canyons because these sectors are oriented dow the regional slope (Fig. 7). Therefore, the distribution of the arrows plotted in Fig. 5 can be interpreted in terms of a well-defined groundwater flow system, running from the northern high-altitude areas to the southern lowlands. The only exceptions to this southward orientation of gullies are three localities in the southern rim of Dao Vallis (Fig. 7B). However, the orientation of the latter can be easily explained by local groundwater flow systems from the neighboring high elevation areas. On the other hand, the constant elevation of gully heads at Nirgal Vallis and the relationships between gully elevation and latitude in Dao Vallis (Gilmore and Phillips, 2002), can be also explained by the role of aquicludes in regional groundwater flow systems driven by a north-south oriented hydraulic gradient.

\subsection{Origin of recent groundwater}

Our regional analysis suggests the existence of volcanic hosted aquifers in the Gorgonum-Newton region. Groundwater flow systems in these volcanic aquifers would require: (1) that subsurface water must be in the liquid state at shallow depths; and (2) that hydraulic heads must be established to support the gradients necessary to drive groundwater flow, and therefore that zones of high hydraulic head be recharged. Therefore, there are two major questions that have to be answered in our model: (1) how can water flow under the expected temperatures?, and (2) how the aquifers recharge? Three mechanisms have been explored regarding the possible sources for subsurface water: (1) melting of near-surface ground ice by solar heating (Mellon and Phillips, 2001); (2) shallow aquifers formed in response to global geother- 

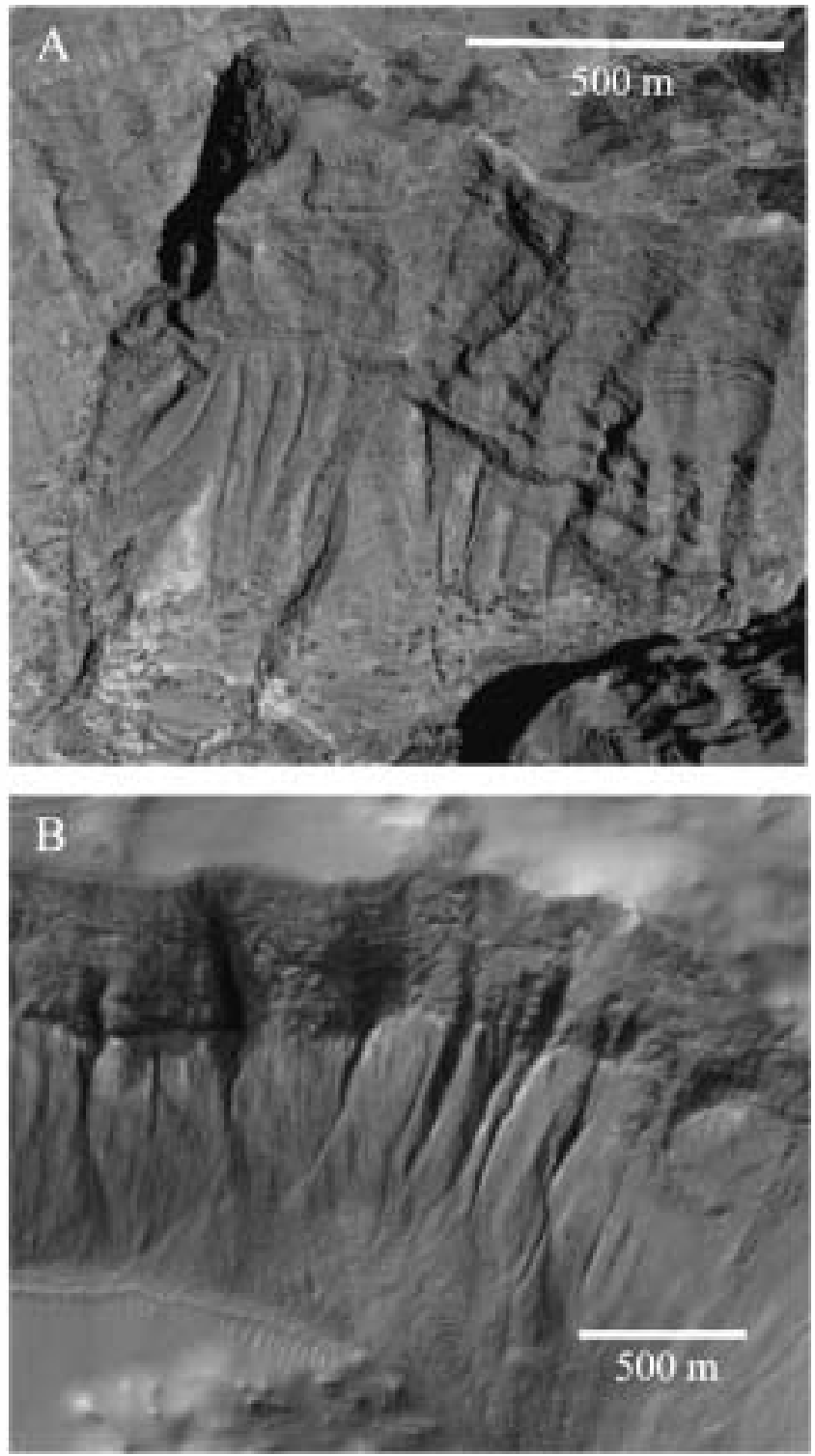

Fig. 6. (A) Aerial photograph of a terrestrial analogue to martian gullies on the walls of Valley of Gran Rey (Southwest of La Gomera, Canary Islands). Groundwater sapping takes place on the walls of the valley in relation to a number of springs localized at the contact between the upper horizontal thick lava flows and underlying dipping older lava flows, which have a much lower permeability due to alteration processes. Note the striking analogy with martian gullies (B) occurring on a crater wall in the Mariner Crater region $\left(35.6^{\bullet} \mathrm{S}, 165.1^{\bullet} \mathrm{W}\right.$, MOC image E 200757$)$.

mal heating (Mellon and Phillips, 2001); and (3) melting of permafrost at shallow depths due to localized geothermal heating (Hartmann, 2001).

The geothermal activity model of Hartmann (2001) could explain the regional cluster of gullies in the GorgonumNewton region. This model would require a regional thermal event taking place in the area in recent time. One possible heat source for this geothermal event could be the alleged giant dikes present beneath Sirenum Fossae faults (Wilson and Head, 2002). However, the age of Sirenum Fossae is probably older than Amazonian (Wilson and Head, 2002), which implies that the putative dikes would have been emplaced more than 3000 Ma ago (Hartmann and Neukum, 2001).

The global geothermal heating model (Mellon and Phillips, 2001; Heldmann and Mellon, 2004) does not require the existence of recent local geothermal events, but needs a dry overburden soil and materials with low thermal conductivities in the subsurface to maintain liquid groundwater. The thermal conductivities proposed by Heldmann and Mellon (2004) to justify the existence of liquid water at shallow depths (from 0.07 to $0.893 \mathrm{~W} \mathrm{~m}^{-1} \mathrm{~K}^{-1}$ ) may be plausible for the upper dry soil, however, they are too low to represent geologic materials forming the aquifer. Thermal conductivity data (Schon, 2004) for the most likely geologic materials hosting the aquifer have much higher thermal conductivities (lava: 0.2-4.6; basalt: 0.44-5.33; pumice: dry 0.25-moist 0.5 ; sandstone: dry 0.67 -moist 7.41 ; sand: 0.1 dry -4.75 moist; clay: dry $0.14-2.6 \mathrm{~W} \mathrm{~m}^{-1} \mathrm{~K}^{-1}$ ). However, Heldmann and Mellon (2004) argue that low conductivity values are consistent with the expected average thermal conductivity derived from a composite subsurface material including a combination of rock and loosely consolidated soil. However, by using values of thermal conductivities similar to those of terrestrial volcanic rocks (between 0.2 and $5 \mathrm{~W} \mathrm{~m}^{-1} \mathrm{~K}^{-1}$ ), the temperatures suggested by Heldmann and Mellon (2004) for the shallow martian subsurface are probably overestimated, and therefore the $273 \mathrm{~K}$ isotherm could not be located in the shallow depths where gullies occur.

On the other hand, the spatial distribution of gullies in the Gorgonum-Newton region, mimicking the topography, is what we would expect from aquifers recharged from the surface, i.e., via melting of near-surface ground ice or superficial snow deposits. This model, advocating the melting of near-surface ground ice by solar heating has been explored by Mellon and Phillips (2001). They propose that even at high obliquity times the martian atmosphere remains too dry for the ground ice to melt, and consequently, ice sublimates before reaching melting temperatures. Therefore, near-surface ground ice is an unlikely candidate for recharging the proposed martian aquifers.

We will explore now an alternative scenario, different to those advocating in situ melting of either permafrost (at shallow depths due to global or localized geothermal heating) or near-surface ground ice (by solar heating). To do this we must first review the proposals for recent climatic changes on Mars due to variations in planetary orbital parameters (e.g., Mustard et al., 2001; Laskar et al., 2002; Head et al., 2003). The work of Head et al. (2003) offers a sound scenario for the stability of ice at martian polar regions and mid-latitudes in concert with the orbital variations. This includes water removal from the poles at high obliquity $\left(>30^{\circ}\right)$ periods and its transfer to mid-latitudes, where it would nucleate on dust particles and become deposited over the martian surface as ice deposits. According to that work, Mars would have undergone an ice age at about 2100-400 kyr BP (when obliquity regularly exceeded $30^{\circ}$ ), resulting in formation of a dusty ice mantle between the $30^{\circ}$ and $60^{\circ}$ lati- 


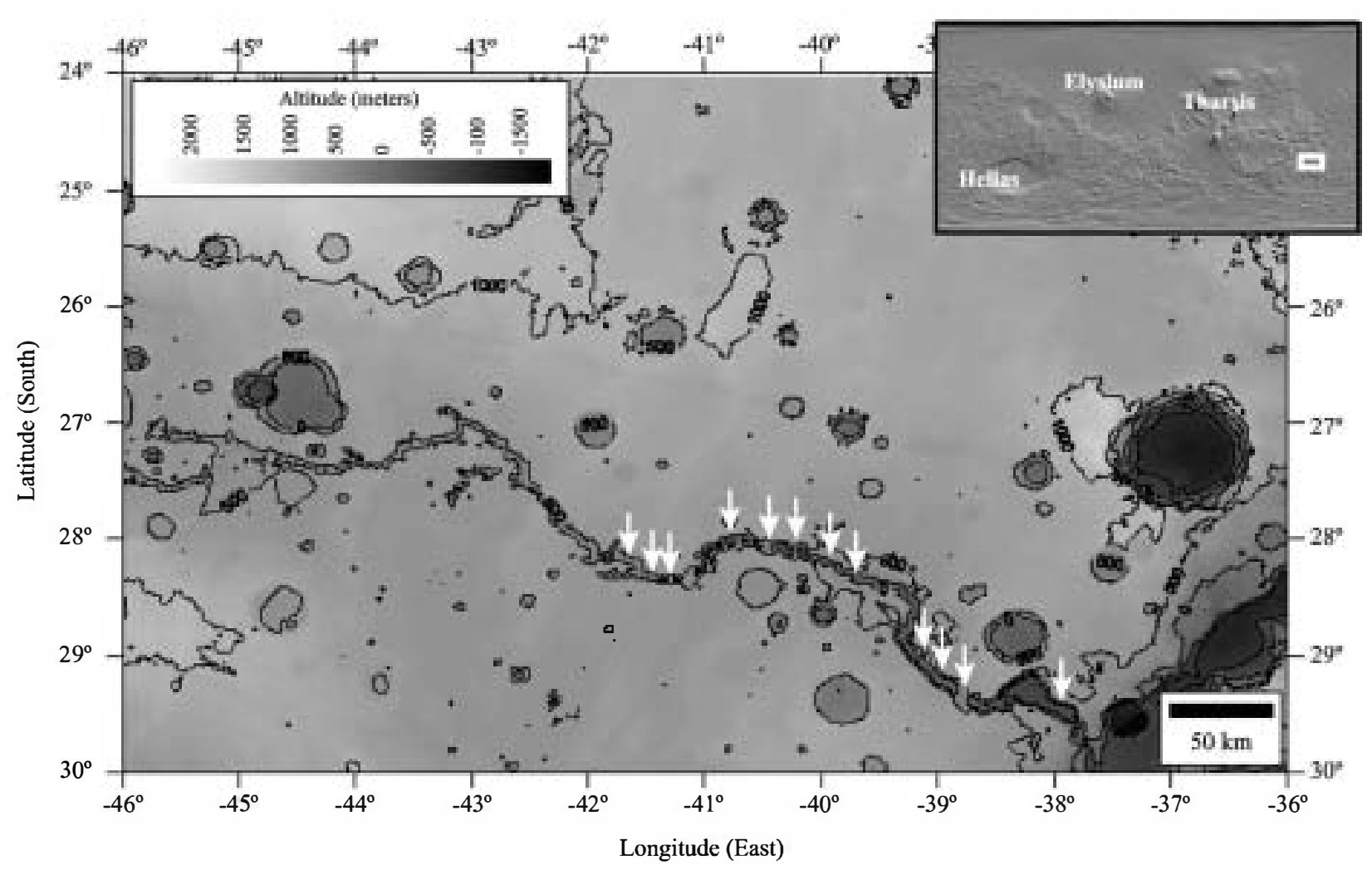

(A)

Fig. 7. MOLA-derived topographic maps of Nirgal (A) and Dao (B) Vallis (see inlets for location at a broader scale), showing the orientation of gully systems occurring on the walls of the canyons. Note that in both cases gullies orientation follow the regional north-south slope, as can be expected in a groundwater-type model. The four locations on the southern wall of Dao Vallis can be easily explained by local groundwater systems flowing from the neighbor high elevations.

tude bands (Mustard et al., 2001), precisely the region where gullies appear (Malin and Edget, 2000). However, from 300 kyr BP onwards (interglacial period), the obliquity has been always near $25^{\circ}$, and the mid-latitude ice mantle would have been steadily retreating and disappearing, with part of this water being transferred back to the polar regions. Thus, the periodic climatic instability of the mid-latitude region could make it a plausible candidate to have produced the water required to recharge a recent martian aquifer, and in fact, we have found clear ground indicators for ice-dust blanket removal in the highlands of Gorgonum-Newton (Fig. 8). It has been previously suggested that at martian mid-latitudes ice-dust surface ice packs can melt, either during the high obliquity periods (Costard et al., 2002), or even at present times (Clow, 1987; Christensen, 2003). The first hypothesis proposes that to melt surface dusty ice patches, daily average temperatures above $0^{\circ} \mathrm{C}$ would be required, which can be only achieved at $30-50^{\circ} \mathrm{S}$ latitude during high obliquity periods in southward oriented slopes (Costard et al., 2002). In addition, Mellon and Phillips (2001) have shown that during these high obliquity periods the maximum surface temperatures at $30^{\circ}-50^{\circ} \mathrm{S}$ latitude are well above $0^{\circ} \mathrm{C}$ for any slope orientation. One way or another these deposits have been seasonally exposed to temperatures above $0{ }^{\circ} \mathrm{C}$, which could have induced the melting of the ice blanket, producing liquid water. High-obliquity periods are of the order of $40 \mathrm{kyr}$ (Laskar et al., 2002), which may be long enough to provide enough meltwater to recharge the gully aquifers. Additionally, some authors (Clow, 1987; Christensen, 2003) have proposed that since in dusty snow packs sunlight is absorbed at depth rather at the surface, the melting of these deposits would take place even at present during the summer midday if the dust levels in the snow are high enough.

Thus, melting of ice blanket deposits at the base, either at present or during high-obliquity periods, could have produced liquid water, which in turn would have percolated to the subsurface and flowed to the basins due to the hydraulic head generated (Fig. 9). When this groundwater reaches a cliff face, it would seep and mix with the regolith, thus forming the gullies and associated debris flow deposits. Our analysis of MOC images confirms the presence of dusty-ice deposits in the Gorgonum-Newton region showing textures typical of dissected terrains (Fig. 8). Therefore, in the last few millions years ice-rich deposits have been repetitively precipitated and eroded on the Gorgonum-Newton region. Regardless of the possible melting mechanism, i.e., whether this occurred during high-obliquity periods, or if it is also possible under the present conditions, they are both a potential source for meltwater to recharge a groundwater flow system in the area.

Key aspects of this proposal are the following: (1) the amount of water that ice-rich deposits could generate by 


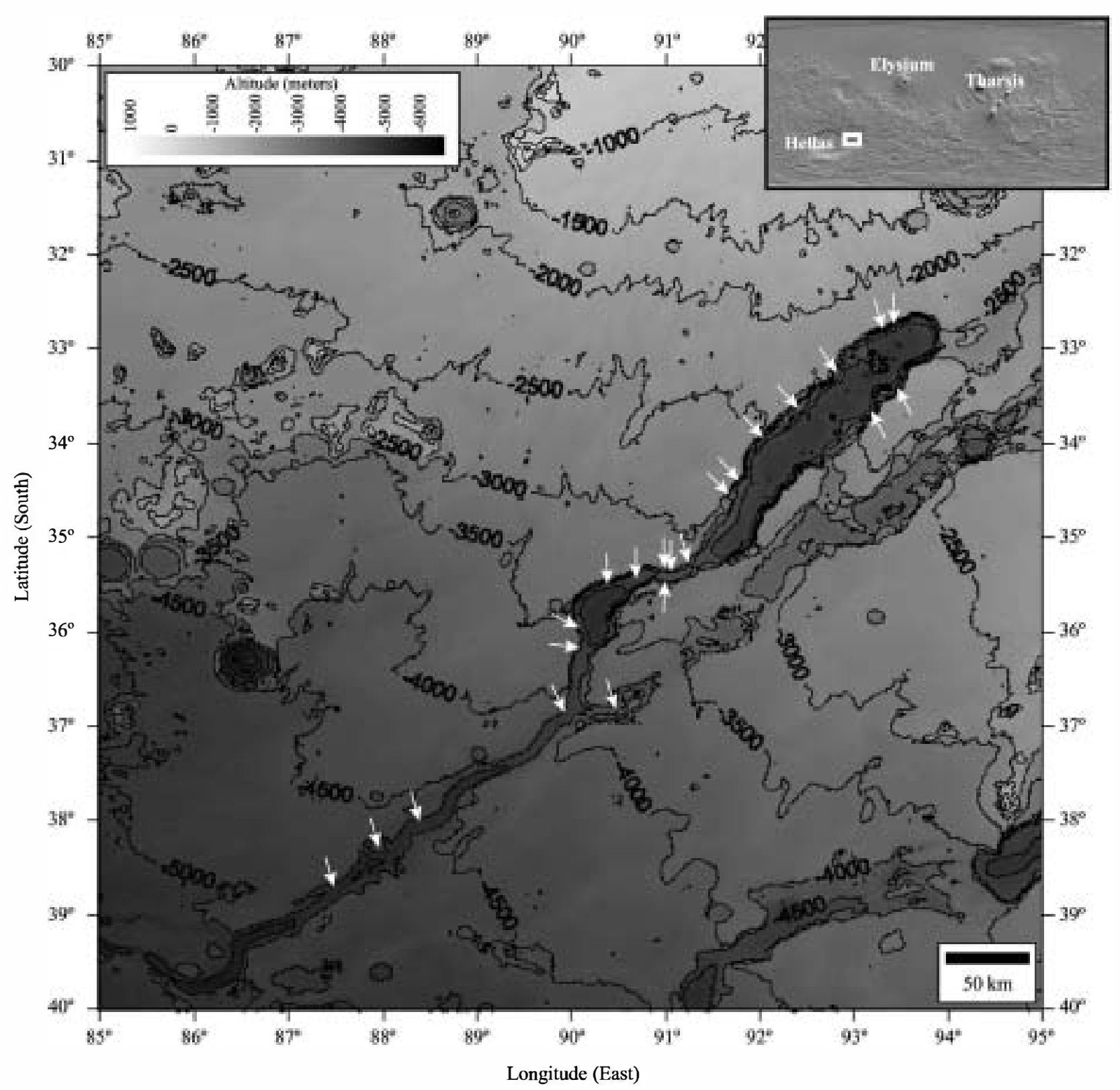

(B)

Fig. 7. (continued)

melting at their base; and (2) whether this amount of water would be enough to explain gully formation. Although numerical models on the behavior of ice and melting processes on Mars have been previously explored (Clow, 1987; Kossacki and Markiewicz, 2004), we do not attempt here to quantitatively estimate the amount of water that could be generated by melting of dusty-ice packs on Mars. Our aim was simpler, to test the possibility of generating gullies with meltwater derived from ice-rich deposits. To achieve this goal we focussed our efforts on a sector located southwest of Newton Basin, where both gullies and proximal dissected terrains (i.e., evidence for ice-rich deposits) can be mapped from MOC images (Fig. 10). We selected two impact craters showing gully systems within contrasting topographic set- tings. The western crater (labeled A on Fig. 10) is located $\sim 50 \mathrm{~km}$ to the west-southwest of Newton Crater, whereas the eastern crater (labeled B on Fig. 10) occur within the walls of Newton Crater, but close to the topographic divide. Following Malin and Edget (2000) we estimated the amount of water required to form the well-developed aprons of gully systems in crater A, obtaining about $4 \times 10^{5} \mathrm{~m}^{3}$ of water involved. According to our proposals, the presence of gullies implies a potential source area from the topographic high. If we take a portion of this high (the $40 \times 7 \mathrm{~km}$ area defined by the dotted line on Fig. 10), and assume that the whole surface was covered by a $5-\mathrm{m}$ thick blanket of ice-rich deposits (e.g., Mustard et al., 2001), we obtain $14 \times 10^{8} \mathrm{~m}^{3}$ of ice-rich materials. Assuming that this dissected terrain 

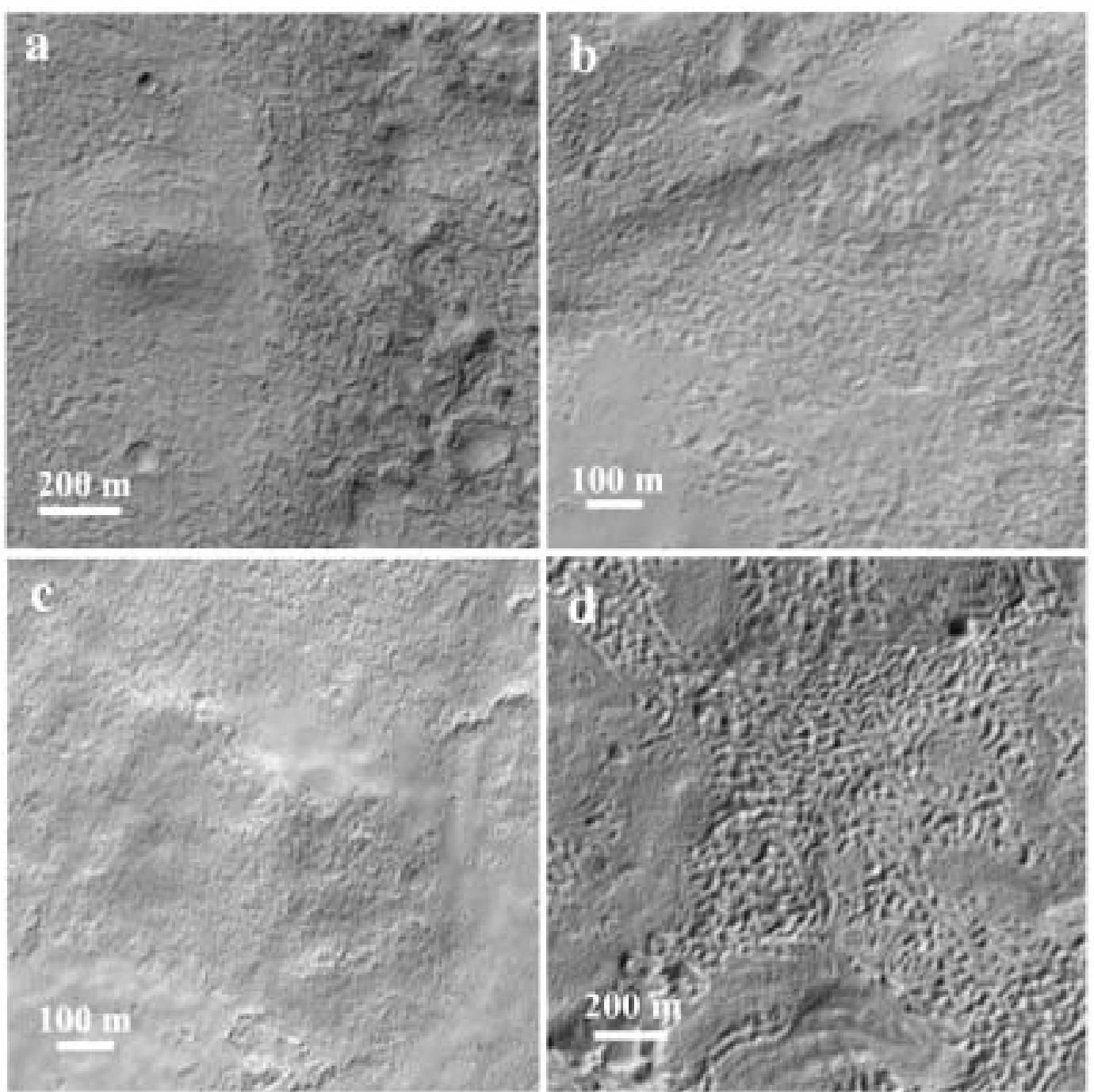

Fig. 8. Examples of dissected terrains (sensu Mustard et al., 2001) seen on the MOC high-resolution images of the Gorgonum-Newton region. See Fig. 1 for location of images. (a) Portion of MOC image E $\mathbf{2 0 0 2 6}$ located on the western side of Gorgonum Basin; (b) portion of MOC image E 200113 located on a high-elevation area south of Mariner Crater; (c) portion of MOC image M1801002 located on the northern rim of Newton Crater; (d) portion of MOC image E201546 located on the highlands of the south-western side of Newton Crater.

contained 50\% (volume) water ice (Head et al., 2003), then $7 \times 10^{8} \mathrm{~m}^{3}$ of ice could have been present on this surface. If we restrict the surface to where the available MOC images show undisputable evidence for the existence of dissected terrains (as defined by the solid line on Fig. 10), then the potential source area has an extension of $185 \mathrm{~km}^{2}$, and may have contained $\sim 4.5 \times 10^{8} \mathrm{~m}^{3}$ of ice. The amount of water ice contained in the ice-rich dissected terrains would be 1000 times greater than the water required to form the gullies observed in crater A. In other words, the observed gullies could have formed if just a $1 / 1000$ of this water ice would have melted, percolated, and flowed following the hydraulic gradient. On the other hand, since crater B is located closer to the topographic divide, much less water would have been involved, and conspicuously, gullies are poorly developed in this area (Fig. 10).

Thus, we suggest that the melting of ice-rich deposits and the subsequent percolation of meltwater could provide a source for groundwater flow, and therefore, may offer a plausible explanation for gully formation. Our suggested link between ice-rich deposits and gullies (via aquifer recharging) also allows explanation for the age of gullies, because it would reflect the recent climatic fluctuations capable of producing and dissecting superficial water-ice deposits at mid-latitudes. However, further modeling on the melting of ice-rich deposits is necessary. For example, if the ground ice melts near the surface the water would have great difficulty to percolate through the snow pack and the cold subsurface soil without refreezing (Heldmam and Mellon, 2004). The next section offers some ideas that may help to elucidate this matter.

\subsection{Flow of recent groundwater}

It is no clear whether the present temperatures could be below freezing (e.g., Squyres et al., 1992) or above $0{ }^{\circ} \mathrm{C}$ 


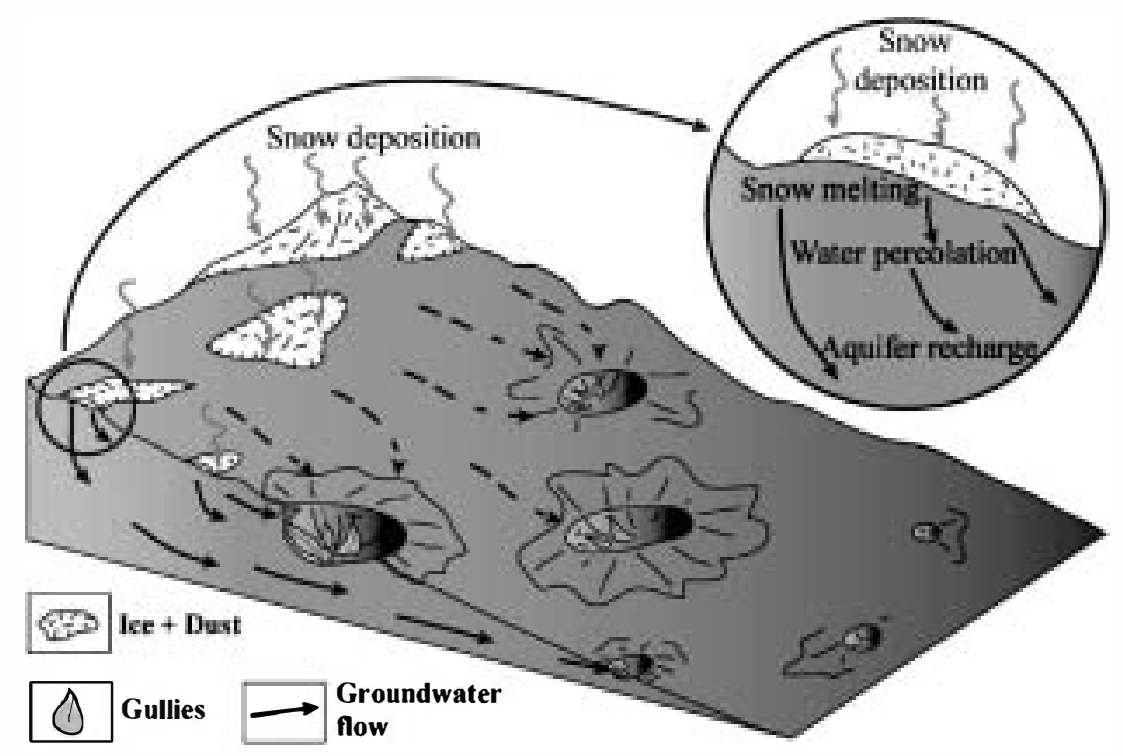

Fig. 9. Idealized scheme depicting the suggested relationships between aquifer formation and groundwater flow from high- to low-elevation lands in mid-latitude terrains. Water recharge of the aquifer would be accomplished by melting of the ice-rich deposits at their base.

(Heldmann and Mellon, 2004) at hundreds of meters below the surface of Mars at the latitudes where gullies occur. Due to this uncertainty, we will concentrate on the following question: can water maintain its liquid integrity under freezing conditions? Regarding this matter, we suggest that the physics of nonequilibrium may provide a plausible explanation for the stability of liquid water within an aquifer under these conditions (Oyarzun et al., 2003). Water contained in porous materials (as we would expect in an aquifer) behaves in a different way to bulk, superficial water. For example, liquid water can be found in soils and other porous media at temperatures as low as $-40{ }^{\circ} \mathrm{C}$, i.e., well below the bulk melting temperatures (Maruyama et al., 1992; Cahn et al., 1992) or even at $-80^{\circ} \mathrm{C}$ in the interstices of shallow hypersaline soils in the Antarctic cold deserts, a plausible equivalent to martian environmental conditions (e.g., WynnWilliams et al., 2001). These phenomena, departing from classic thermodynamics are related to the concept of hysteresis, which basically refers to a retardation of the effect when forces acting upon a body are changed. In the case of liquids the hysteresis freezing temperature, as opposed to the thermodynamic freezing temperature, is defined as the limit of metastability of the liquid phase during freezing (e.g., Radhakrishnan et al., 2000). Liquids can be supercooled below the thermodynamic freezing transition because of the presence of a kinetic barrier to crystallization (Morishigue and Kawano, 1999). This phenomenon is particularly important in small, completely confined spaces where kinetic energy is substantially reduced. In other words, the freezing temperature, as compared to the bulk, can be severely depressed in confined spaces. If dissolved salts are present these effects are enhanced by two mechanisms: (a) further depression of the freezing point, controlled by the concentration and nature of salts in solution (e.g., about $-56^{\circ} \mathrm{C}$ for the $\mathrm{H}_{2} \mathrm{O}-\mathrm{NaCl}-\mathrm{KCl}-\mathrm{CaCl}_{2}$ system; Konnerup-Madsen, 1979); and (b) salt rejection, because pure water tends to freeze at a freezing front, leaving a progressively more concentrated solution (and therefore with an even more depressed freezing point) (e.g., Parameswaran and Mackay, 1996). Thus, nonequilibrium physics operating in porous media could provide a plausible alternative approach to account for the present existence of liquid water on martian aquifers at mid-latitude regions. Ground penetrating radar such as MARSIS (onboard the orbiting Mars Express) and SHARAD (onboard the future Mars Reconnaissance Orbiter), could potentially test if liquid water is flowing at present in the shallow subsurface of the Gorgonum-Newton region.

\section{Conclusions}

The results of our work indicate that the gullies in Gorgonum-Newton region display a pattern following the regional slope consistent with a fully developed groundwater flow system. This pattern is also displayed by gullies in the Dao and Nirgal Vallis regions. In the Gorgonum-Newton region the groundwater would flow from several systems to the low-elevation basins and craters, where most of the gullies are located. The best examples are located in Newton Crater and its surroundings, where gully orientation is mainly radial to the centre of the basin, and also radially distributed from high-elevation sites. We suggest that the source of groundwater in these high-elevation sites could be related to the outcrops of young partially eroded ice-rich deposits. The water resulting from melting of these deposits would percolate and recharge large-scale regional aquifers. The mechanism here proposed does not differ much from those that lead to aquifer recharge on Earth, but would occur at a much larger time-scale, and would not be triggered by seasonal but by global climatic changes. 


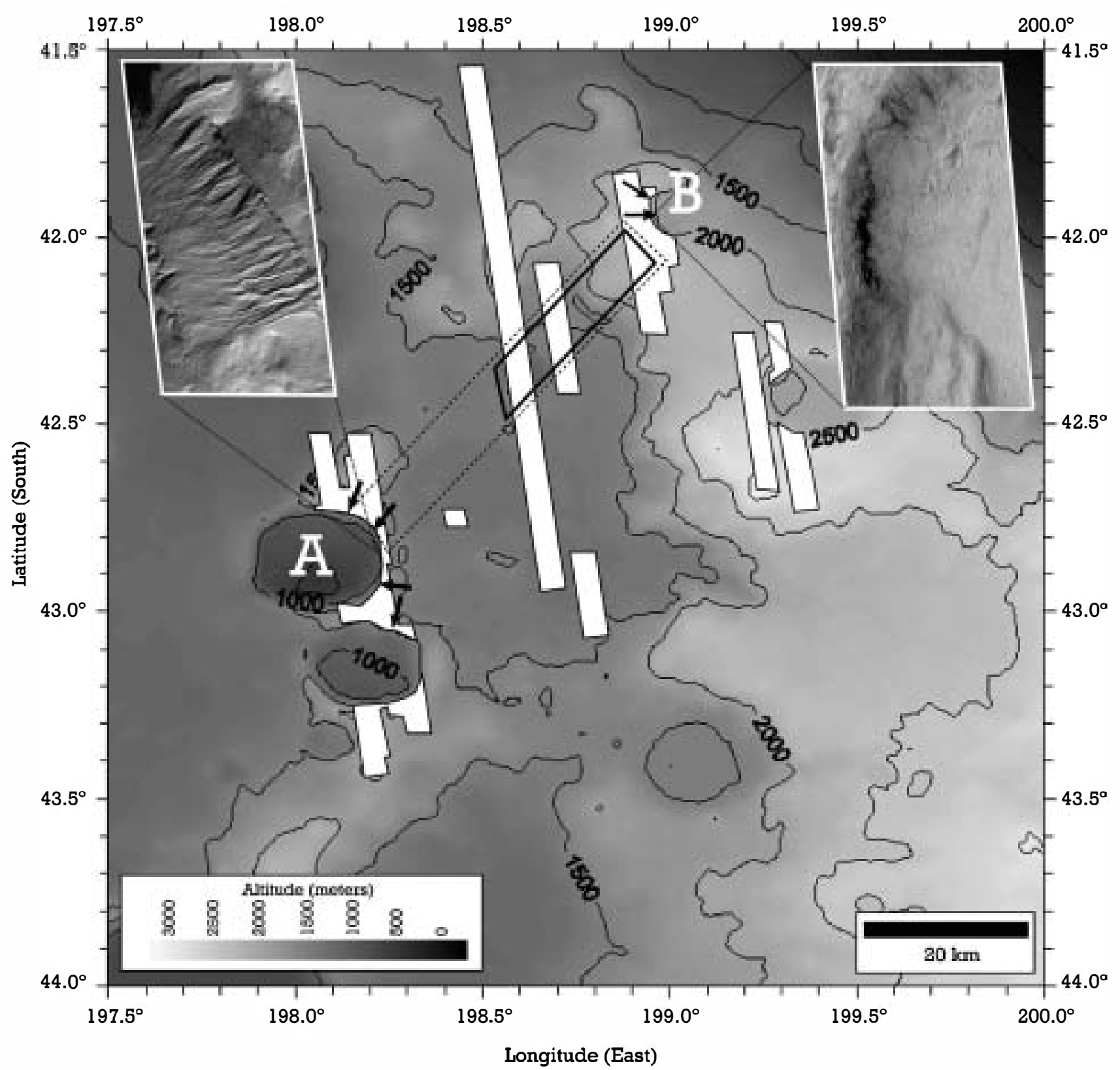

Fig. 10. MOC images showing dissected terrains (white pattern) on a sector of the SW rim of Newton Basin. The area defined by the dotted line shows the maximum potential source for gullies on the NE side of crater A. The solid line defines a more restricted potential area, which is supported by the undisputable occurrence of dissected terrains on MOC images. We have used these two areas to compare the amount of water involved in the gullies, and the amount of percolating water that ice-rich deposits could generate in the area. Our calculations suggest that if just a 1/1000 of the water ice of these deposits would have melted, then gullies on crater A could be explained by percolating groundwater following the regional slope (see text for details). Gullies on crater B are poorly developed because they are located closer to the topographic divide, and therefore have a smaller potential source area.

\section{References}

Baker, V.R., 2001. Water and the martian landscape. Nature 412, 228-236. Cahn, J.W., Dash, J.G., Haiying, F., 1992. Theory of ice premelting in monosized powders. J. Cryst. Growth 123, 101-108.

Carr, M.H., 1996. Water on Mars. Oxford Univ. Press, Oxford, p. 217.

Christensen, P.R., 2003. Formation of recent martian gullies through melting of extensive water-rich snow deposits. Nature 422, 45-48.

Clow, G.D., 1987. Generation of liquid water on Mars through the melting of a dusty snowpack. Icarus 72, 95-127. 
Costard, F., Forget, F., Mangold, N., Peulvast, J.P., 2002. Formation of recent martian debris flow s by melting of near-surface ground ice at high obliquity. Science 295, 110-113.

Edgett, K.S., Malin, M.C., Williams, R.M.E., Davis, S.D., 2003. Polar- and middle-latitude martian gullies: A view from MGS after 2 Mars years in the mapping orbit. Lunar Planet. Sci. XXXIV. Abstract 1038.

Gaidos, E., 2001. Cryovolcanism and the recent flow of liquid water on Mars. Icarus 153, 218-223.

Gilmore, M.S., Phillips, E.L., 2002. Role of aquicludes in formation of martian gullies. Geology 30, 1107-1110.

Hartmann, W.K., 2001. Martian seeps and their relation to youthful geothermal activity. Space Sci. Rev. 96, 405-410

Hartmann, W.K., Neukum, G., 2001. Cratering chronology and the evolution of Mars. Space Sci Rev. 96, 165-194.

Hartmann, W.K., Thorstein sson, T., Sigurdson, F., 2003. Martian hillside gullies and Icelandic analogs. Icarus $162,259-277$.

Head, J.W., Mustard, J.F., Kreslavski, M.A., Milliken, R.E., Marchant, D.R., 2003. Recent ice ages on Mars. Nature 426, 797-802.

Heldmann, J.L., Mellon, M.T., 2004. Observations of martian gullies and constraints on potential formation mechan isms. Icarus 168, 285-304.

Hoffrnan, N., 2000. White Mars: A new model for Mars' surface and atmosphere based on $\mathrm{CO}_{2}$. Icarus 146, 326-342.

Irw in III, R.P., Maxwell, T.A., Howard, A.D., Craddock, R.A., Leverington, D. W., 2002. A large Paleolake Basin at the head of Máadim Vallis, Mars. Science 297, 2209-2212.

Knauth, P.L., Burt, D.M., 2002. Eutectic brimes on Mars: Origin and possible relation to young seepage features. Icarus 158, 267-271.

Konnerup-Madsen, J., 1979. Fluid inclusions in quartz from deep-seated granitic intrusions, south Norway. Lithos 12, 13-23.

Kossacki, K.J., Markiewicz, W.J., 2004. Seasonal melting of surface water ice conden sating in martian gullies. Icarus 171, 272-283.

Laskar, J., Levrard, B., Mustard, J., 2002. Orbital forcing of the martian polar layered deposits. Nature 419, 375-377.

Lee, P., McKay, C.P., Matthews, J., 2002. Gullies on Mars: Clues to their formation timescales from possible analogs from Devon Island, Nanavut, artic Canada. Lunar Planet. Sci. XXXIII. Abstract 2050.

Malin, M.C., Edget, K.S., 2000. Evidence for recent groundwater seepage and surface runoff on Mars. Science 288, 2330-2335.

Maruyama, M., Bien fait, M., Dash, J.G., Coddens, G., 1992. Interfacial melting of ice in graphite and talc powders. J. Cryst. Growth 118, 3340.
Mellon, M.T., Phillips, R.J., 2001. Recent gullies on Mars and the source of liquid water. J. Geophys. Res. 106, 23165-23179.

Morishigue, K., Kawano, K., 1999. Freezing and melting of water in a single cylindrical pore: The pore-size dependence of freezing and melting behavior. J. Chem. Phys. 110, 4867-4872.

Musselwhite, D.S., Swindle, T.D., Lunine, J.L., 2001. Liquid $\mathrm{CO}_{2}$ breakout and the formation of recent small gullies on Mars. Geophys. Res. Lett. 28, 1283-1285.

Mustard, J.F., Cooper, C.D., Rifkin, M.K., 2001. Evidence for recent climate change on Mars from the identification of youthful near-surface ground ice. Nature 412, 411-414.

Oyarzun, R., Viedma, C., Márquez, A., Lillo, J., 2003. Freezing-resistant liquid water in porous media, a possible mechanism to account for the fluidized tran sport of sediments on Mars: An example from East Gorgonum Crater. Terra Nova 15, 238-242.

Parameswaran, V.R., Mackay, J.R., 1996. Electrical freezing potentials measured in a pingo growing in the western Canadian Artic. Cold Regions Sci. Technol. 24, 191-203.

Radhakrishnan, R., Gubbin s, K.E., Sliwinska-Bartkowiak, M., 2000. Effect of the fluid-wall interaction on freezing of con fined fluids: Toward the development of a global phase diagram. J. Chem. Phys. 112, 11048 11057.

Schon, J.H., 2004. Physical Properties of Rocks: Fundamentals and Principles of Petrophysics. Elsevier, Amsterdam, p. 582.

Scott, D.H., Tanaka, K.L., 1986. Geologic map of the western equatorial region of Mars. Geologic Investigations Series Maps I-1802-A, USGS.

Squyres, S.W., Clifford, S.M., Kuzmin, R.O., Zimbelman, J.R., Costard, F.M., 1992. Ice in the martian regol ith. In: Kieffer, H.H., Jakosky, B.M., Snyder, C.W., Matthews, M.S. (Eds.), Mars. Univ. of Arizona Press, Tucson, pp. 523-554.

Treimann, A.H., 2003. Geologic settings of martian gullies: Implications for their origin. J. Geophys. Res. 108 (E4), doi:10.1029/2002JE 01900 .

Wil son, L., Head III, J.W., 2002. Tharsis radial graben system as the surface manifestation of plume-related dike intrusion complexes: Models and implication s. J. Geophys. Res 107 (E8), doi:10.1029/2001 JE01593.

Wynn-Williams, D.D., Cabrol, N.A., Grin, E.A., Haberle, R.M., Stoker, C.R., 2001. Brines in seepage channels as eluants for surface relicts biomolecules on Mars? Astrobiology 1, 165-184. 